\title{
Antidepressive legemidler - klinisk praksis må endres
}

\author{
Antidepressive legemidler er mindre effektive enn det det omfattende forbruket skulle tilsi. Preparatene er \\ beheftet med bivirkninger som tilsier større forsiktighet i forskrivningen.
}

Arne E. Vaaler

arne.e.vaaler@ntnu.no

Ole Bernt Fasmer

Antidepressive legemidler kan redusere symptomer ved depresjon, men de kan også ha en utilfredsstillende effekt eller medføre alvorlig forverring (1). Kunnskap om effekter og alvorlige bivirkninger av preparatene bør ha konsekvenser for forskrivningspraksis.

Antidepressiver er blant de mest forskrevne medikamenter på verdensbasis. Den omfattende bruken kan til dels ses på som et uttrykk for den økende medikaliseringen av det moderne samfunnet (2). Også i Norge er forbruket høyt og stigende (3).

Antidepressiver finnes i en rekke hovedtyper. Vår fremstilling i denne kronikken er i prinsippet dekkende for alle hovedtyper, men de fleste referanser henviser til såkalte selektive serotoninreopptakshemmere (SSRI) og serotonin-noradrenalinreopptakshemmere (SNRI). Disse er i store trekk likeverdige når det gjelder grad og type av bivirkninger (4-6).

\section{Effekter}

Det er publisert hundrevis av klinisk randomiserte studier som gir statistisk signifikante resultater til fordel for antidepressive legemidler (7). Studiene har i varierende grad svakheter i bl.a. design, inklusjonskriterier, effektmål, studiepopulasjoner, oppfølgingstid, dataregistrering og statistikkbruk $(7,8)$.

Nye metaanalyser tilsier at antidepressive legemidler er mindre effektive enn tidligere antatt og det omfattende forbruket skulle tilsi (7, 9-11). Turner og medarbeidere har påvist en betydelig seleksjonsskjevhet til fordel for studier hvor antidepressiver har kommet positivt ut sammenliknet med placebo. Studier med ufordelaktige resultater for preparatene har tendens til å forbli upublisert (9).

Sammenliknet med placebo fant Kirsch og medarbeidere en effekt til fordel for antidepressiver bare for de mest syke pasientene. I denne populasjonen var hovedforskjellen mindre effekt av placebo (10). Fournier og medarbeidere fant at antidepressiver sammenliknet med placebo hadde liten effekt for pasienter med lette eller moderate depresjoner, men for pasienter med meget alvorlige depresjoner var effekten betydelig (11). De ulike publiserte sammenlikningene mellom antidepressiver og placebo viser en klar tendens, nemlig at de positive effektene av preparatene $i$ forhold til placebo var større i eldre studier enn i nyere arbeider (12). Årsaken til dette er uklar, men lavere utgangsverdi i depresjonsmål i nye studier kan forklare noe (12).

\section{Bivirkninger}

Randomiserte, kliniske studier av antidepressive legemidler har vært styrt av legemiddelfirmaer og designet for å vise korttidseffekt og ikke sikkerhet ved bruk over lang tid (13). Det har ikke vært mye oppmerksomhet rundt det å avdekke bivirkninger og skader av preparatene (7). Det er

\section{«Det er viktig at både forskning og praksis foregår uten binding til legemiddelindustrien»}

en ubalanse mellom vektlegging av positive og negative effekter (14). En rekke alvorlige bivirkninger i kliniske studier er enten ikke rapportert eller feilaktig rapportert (15). Vi har likevel nå data som tilsier økt grad av forsiktighet i forskrivningspraksis.

Fra 2004 har de amerikanske legemiddelmyndighetene (FDA) publisert flere sikkerhetsadvarsler om mulig økt suicidal intensjon ved bruk av antidepressive legemidler hos barn, ungdom og unge voksne (13). Alle slike preparater skal siden 2007 ha en såkalt svart boks-advarsel (black box warning) som informerer om økt fare for suicidale symptomer. Denne problemstillingen ble reist allerede i 1958 (15). SSRI-indusert suicidal intensjon som klasseeffekt av antidepressive legemidler har vært kjent fra tidlig i 1990-årene (16). En nylig publisert norsk studie blant pasienter med bipolar lidelse viste at suicidfors $ø \mathrm{k}$ i sykehistorien er assosiert med tidligere bruk av antidepressive legemidler (17).

Hvorvidt slike preparater totalt sett øker antall selvmord hos unge og voksne må fortsatt sies å være uavklart (18). Healy \& Aldred fant i sin oversiktsartikkel at risiko for suicid ved behandling med antidepressive legemidler er 2-3 ganger så høy sammenliknet med placebo (15). Årsaken til forøket suicidal intensjon ved bruk av antidepressiver er ikke sikkert påvist, men en rekke forfattere antyder en relasjon til spesifikke undergrupper og en assosiasjon mellom medikament indusert psykomotorisk agitasjon, «tankekjør» og suicidal atferd $(1,19)$.

I likhet med antipsykotika kan antidepressive legemidler gi akatisi, dvs. manglende evne til å sitte stille, sterk rastløshet og trang til å vandre rundt $(16,20)$. Flere studier viser at intense, gjerne kortvarige affektive tilstander preget av desperasjon, angst, agitasjon og sinne gir kriser med høy risiko for suicidal atferd (21). En rekke svært suicidale pasienter tenderer til å benekte suicidal intensjon i samtale med behandler. Tilstedeværelse av alvorlig angst og agitasjon er nå den eneste sikre prediktor for suicid under innleggelse i sykehus og like etter utskrivning (22).

Antidepressiver har en rekke psykoaktive effekter og bivirkninger spesielt de første dager etter behandlingsstart eller doseendring (6). Noen pasienter får paradoksale effekter, inkludert forsterkning av depressive symptomer (23). En studie fra USA viste at rundt $8 \%$ av innleggelser i et psykiatrisk sykehus hadde sin årsak i mani eller psykose indusert av antidepressive legemidler (24).

Legemiddelinformasjon om ulike medikamenter gir relativt hyppig advarsler om atferdsendring med mulighet for vold mot andre. De fleste antidepressiver har hatt en slik informasjon. I en ny studie har Moore og medarbeidere analysert data fra meldesystemet for legemiddelbivirkninger i USA (25). De fant at vold mot andre totalt sett er assosiert med få legemidler. Antidepressive legemidler med serotonerge effekter hadde den sterkeste assosiasjon til slike voldelige hendelser. 


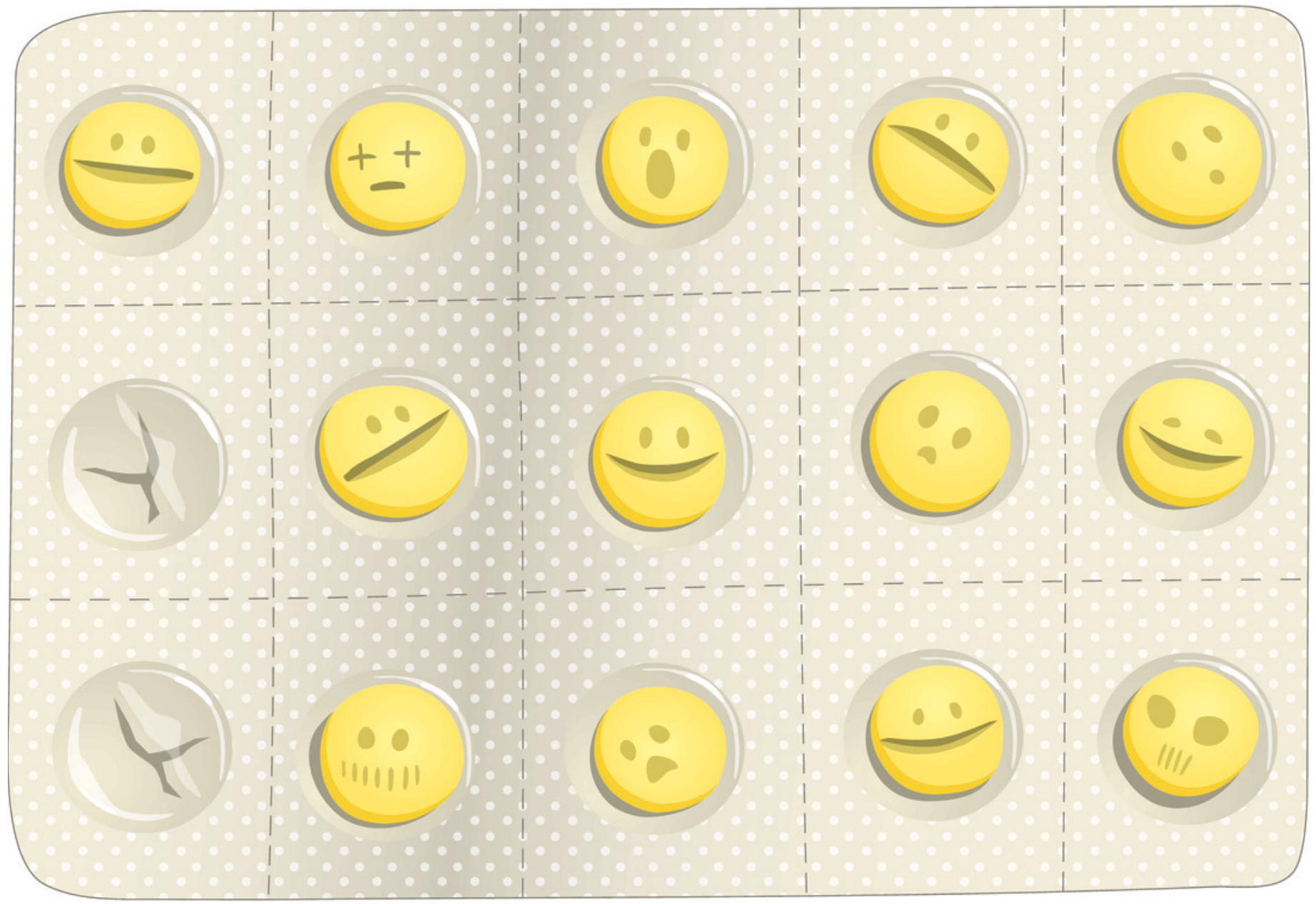

\section{Toleranseutvikling}

Antidepressive legemidler kan gi toleranseutvikling. Dette viser seg først og fremst ved seponering (26). De fleste symptomer er relativt kortvarige. Det er også beskrevet kronisk, tardiv dysfori etter langtidsbruk av antidepressive legemidler på samme måte som tardiv dyskinesi etter dopaminblokade (27). Pasientene har gjerne innledningsvis en positiv effekt av medikamentet. Etter hvert tapes denne effekten og kroniske, terapiresistente tilstander kan utvikles (28).

Klinisk er det viktig å ta hensyn til toleranseutvikling når antidepressiver seponeres. En rekke pasienter får da økt symptomtrykk. Dette kan lett feiltolkes som residiv.

\section{Diskusjon}

Det er mange holdepunkter for å anta at det er et overforbruk av antidepressive lege- midler i norsk praksis. En viktig grunn til dette kan være en til dels ukritisk markedsføring fra legemiddelindustrien. De fleste studier er designet for å finne effekter til fordel for preparatene, små og klinisk tvilsomt signifikante effekter blir ofte blåst opp, mens bivirkninger bagatelliseres og det er vanskelig å nå frem med kritiske argumenter. Dette har mye til felles med Chomskys beskrivelser av propaganda og dens virkemidler $(18,29)$.

Vi har behov for uavhengig, klinisk forskning. Det er viktig at både forskning og praksis foregår uten binding til legemiddelindustrien. Mest av alt trenger vi legemiddelinformasjon fra uavhengige kilder. Tilgang på slik informasjon vil kunne endre forskrivningspraksis.

Antidepressive legemidler er til god hjelp ved noen depressive tilstander. Spørsmålet er hvilke. Vi mangler sikre data. Det er lettere å ha en mening om hvem som ikke skal ha slike preparater. Pasienter med bipolar depresjon bør ikke ha antidepressiver, i alle fall ikke uten samtidig bruk av stemningsstabiliserende medikasjon. Hos pasienter med depresjoner ledsaget av agitasjon, betydelig angst eller desperasjon bør behandling med antidepressive legemidler gjennomføres med stor forsiktighet (22), særlig som monoterapi. Hvis slike symptomer dukker opp under behandling med antidepressiver, må behandlingen straks revurderes.

Dosering og serumkonsentrasjoner av antidepressiver er påfallende lite påaktet. Høye doseringer er hyppig (30). Det er indikasjoner på at noen preparater har antikonvulsive effekter i lav dosering og prokonvulsive effekter i høyere dosering (31). Det er også data som tyder på at noen antidepressive legemidler har et terapeutisk vindu som tilsier at preparatene ikke har noen effekt 
eller bare har uønskede effekter under og over et visst doseringsintervall (32).

Antidepressive legemidler bør vurderes seponert hos pasienter som har brukt slike preparater lenge. Pasientene må informeres nøye om toleranseutvikling og seponeringsreaksjoner. Symptomer etter seponering er sjelden uttrykk for tilbakefall. Effekten av slike preparater etter mer enn seks måneders behandling er ikke vitenskapelig dokumentert (27). Dosen bør trappes gradvis ned hos pasienter som har brukt preparatene lenge. Det finnes noe dokumentasjon for at stemningsstabiliserende antiepileptika kan ha effekt som behandling mot seponeringsreaksjoner, både som monoterapi og i kombinasjon med antidepressiver ved nedtrapping (26).

Pasientene som behandles med antidepressive legemidler må følges nøye opp etter behandlingsstart, ettersom de fleste alvorlige hendelser kommer de første 12 uker av behandlingen (33). Fast, individuell og hyppig oppfølging og kontroll er helt nødvendig.

\section{Arne E. Vaaler (f. 1954)}

er førsteamanuensis ved Norges teknisknaturvitenskapelige universitet og overlege ved Seksjon for akuttpsykiatri, St. Olavs hospital. Forfatter har fylt ut ICMJE-skjemaet og oppgir ingen interessekonflikter.

\section{Ole Bernt Fasmer (f. 1952)}

er professor dr.med. og leder ved Seksjon for psykiatri, Institutt for klinisk medisin, Universitetet i Bergen og undervisningsansvarlig i Psykiatrisk divisjon, Helse Bergen. Forfatter har fylt ut ICMJE-skjemaet og oppgir ingen interessekonflikter.

\section{Litteratur}

1. Fava GA. The intellectual crisis of psychiatric research. Psychother Psychosom 2006; 75: 202-8.

2. Lacasse JR, Leo J. Serotonin and depression: a disconnect between the advertisements and the scientific literature. PLoS Med 2005: 2: e392.
3. Reseptregisteret. Oslo: Nasjonalt folkehelseinstitutt, 2012. www.reseptregisteret.no/ (10.1.2013).

4. Schneeweiss S, Patrick AR, Solomon DH et al. Variation in the risk of suicide attempts and completed suicides by antidepressant agent in adults: a propensity score-adjusted analysis of 9 years data. Arch Gen Psychiatry 2010; 67: 497-506.

5. Schatzberg AF. Safety and tolerability of antidepressants: weighing the impact on treatment decisions. J Clin Psychiatry 2007; 68 (suppl 8): 26-34.

6. Goldsmith L, Moncrieff J. The psychoactive effects of antidepressants and their association with suicidality. Curr Drug Saf 2011; 6: 115-21.

7. Ioannidis JP. Effectiveness of antidepressants: an evidence myth constructed from a thousand randomized trials? Philos Ethics Humanit Med 2008; 3: 14

8. Ghaemi SN. Statistics and epidemiology in mental health. Measuring truth and uncertainty. New York: Cambridge University Press, 2009

9. Turner EH, Matthews AM, Linardatos E et al. Selective publication of antidepressant trials and its influence on apparent efficacy. N Engl J Med 2008: 358: 252-60.

10. Kirsch I, Deacon BJ, Huedo-Medina TB et al. Initia severity and antidepressant benefits: a meta-analysis of data submitted to the Food and Drug Administration. PLoS Med 2008; 5: e45.

11. Fournier JC, DeRubeis RJ, Hollon SD et al. Antidepressant drug effects and depression severity: a patient-level meta-analysis. JAMA 2010; 303: 47-53

12. Khin NA, Chen Y-F, Yang Y et al. Exploratory analyses of efficacy data from major depressive disorder trials submitted to the US Food and Drug Administration in support of new drug applications. J Clin Psychiatry 2011: 72: 464-72.

13. Friedman RA, Leon AC. Expanding the black box-depression, antidepressants, and the risk of suicide. N Engl J Med 2007; 356: 2343-6.

14. Papanikolaou PN, Churchill R, Wahlbeck K et al. Safety reporting in randomized trials of mental health interventions. Am J Psychiatry 2004; 161 1692-7

15. Healy D, Aldred G. Antidepressant drug use \& the risk of suicide. Int Rev Psychiatry 2005; 17: $163-72$

16. Lane RM. SSRI-induced extrapyramidal sideeffects and akathisia: implications for treatment. J Psychopharmacol 1998; 12: 192-214

17. Finseth PI, Morken G. Andreassen OA et al. Risk factors related to lifetime suicide attempts in acutely admitted bipolar disorder inpatients Bipolar Disord 2012; 14: 727-34

18. Balon R. Selective serotonin reuptake inhibitors and suicide: is the evidence, as with beauty, in the eye of the beholder? Psychother Psychosom 2003 72: $293-9$.

19. Benazzi F. Suicidal ideation and depressive mixed states. Psychother Psychosom 2005; 74: 61-2.

20. Hansen L. A critical review of akathisia, and its possible association with suicidal behaviour. Hum Psychopharmacol 2001; 16: 495-505.

21. Hendin H, Maltsberger JT, Szanto K. The role of intense affective states in signaling a suicide crisis. J Nerv Ment Dis 2007; 195: 363-8.

22. Busch KA, Fawcett J, Jacobs DG. Clinical correlates of inpatient suicide. J Clin Psychiatry 2003; 64: 14-9.

23. Reeves RR, Ladner ME. Antidepressant-induced suicidality: implications for clinical practice. South Med J 2009; 102: 713-8

24. Preda A, MacLean RW, Mazure CM et al. Antidepressant-associated mania and psychosis resulting in psychiatric admissions. J Clin Psychiatry $2001 ; 62: 30-3$

25. Moore TJ, Glenmullen J, Furberg CD. Prescription drugs associated with reports of violence towards others. PLoS ONE 2010; 5: e15337.

26. Chouinard G, Chouinard VA. Atypical antipsychotics: CATIE study, drug-induced movement disorder and resulting iatrogenic psychiatric-like symptoms, supersensitivity rebound psychosis and withdrawal discontinuation syndromes. Psychother Psychosom 2008; 77: 69-77.

27. El-Mallakh RS, Briscoe B. Studies of long-term use of antidepressants: how should the data from them be interpreted? CNS Drugs 2012; 26 97-109.

28. El-Mallakh RS, Gao Y, Jeannie Roberts R. Tardive dysphoria: the role of long term antidepressant use in-inducing chronic depression. Med Hypotheses 2011; 76: 769-73.

29. Chomsky N. Media control: the spectacular achievments of propaganda. New York: Seven Stories Press, 1997

30. Medawar C. Herxheimer A. A comparison of adverse drug reaction reports from professionals and users, relating to risk of dependence and suicidal behaviour with paroxetine. Int J Risk Saf Med 2003; 16: 15-9

31. Kondziella D, Alvestad S, Vaaler A et al. Which clinical and experimental data link temporal lobe epilepsy with depression? J Neurochem 2007; 103 2136-52.

32. Fava GA Offidani $E$. The mechanisms of tolerance in antidepressant action. Prog Neuropsychopharmacol Biol Psychiatry 2011; 35: 1593-602.

33. Valenstein M, Kim HM, Ganoczy D et al. Higherrisk periods for suicide among VA patients receiving depression treatment: prioritizing suicide prevention efforts. J Affect Disord 2009; 112: 50-8.

Mottatt 21.9. 2012, første revisjon innsendt 13.11 2012, godkjent 7.1. 2013. Medisinsk redaktør Petter Gjersvik.

Engelsk oversettelse på www.tidsskriftet.no 